Responsabilité rédactionnelle: FMH SERVICES

\title{
Sparen Sie Geld und Aufwand!
}
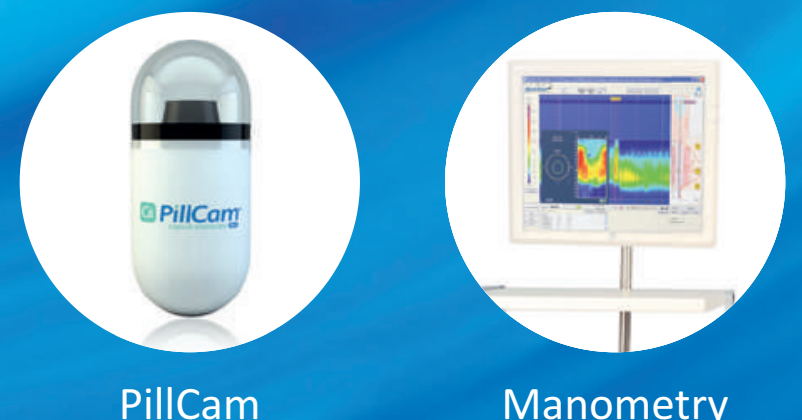

Manometry

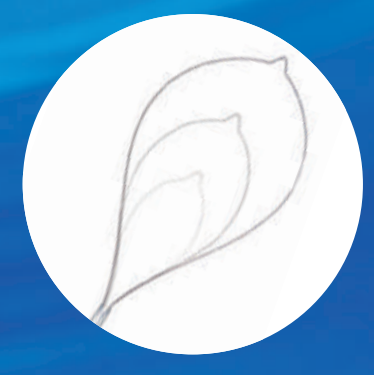

Instruments

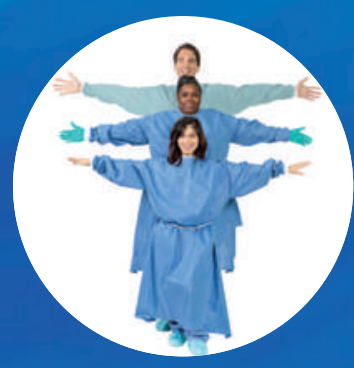

Hygiene

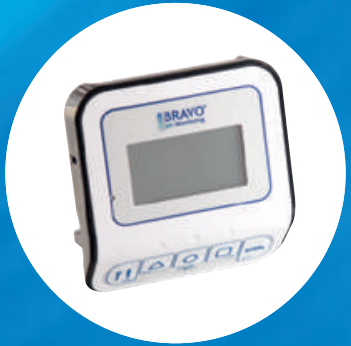

$\mathrm{pH}$

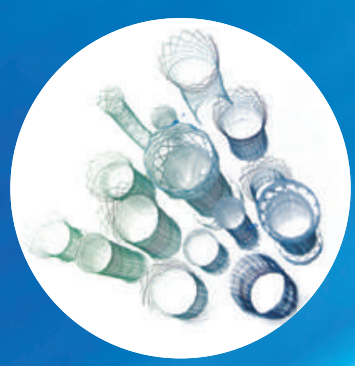

Bonastents

Unser Vertragslieferant Lasermed beliefert Sie mit anspruchsvoller Medizintechnik und Verbrauchsgütern mit Fokus auf Gastroenterologie zu Topkonditionen.

Ihre Vorteile:

- $5 \%$ Kundenrabatt auf all Ihre Bestellungen bei Lasermed

- Zusätzlich bis zu 2 \% Rabatt für Neukunden im ersten Jahr auf alle Einkäufe

- Monatliche Sammelrechnung mit verlängerter Zahlungsfrist

- Direktbestellung bei unserer grossen Auswahl von Vertragslieferanten (www.fmhservices.ch)

lasermed

www.lasermed.ch

\section{GEMEINSAMER EINKAUF FÜR ÄRZTINNEN UND ÄRZTE}

$\square$ Ich möchte von den vorteilhaften Konditionen der Lasermed profitieren und über den gemeinsamen Einkauf von FMH Consulting Services bei Lasermed einkaufen.

$\square$ Ich bin interessiert und habe Fragen. Bitte rufen Sie mich an.

Vorname / Name

Adresse

PLZ / Ort

Telefon privat / geschäftlich

Beste Zeit für einen Anruf

E-Mail-Adresse

Ort, Datum

Unterschrift

\section{FMH CONSULTING SERVICES}

FMH Consulting Services AG Burghöhe 1, 6208 Oberkirch Tel. 0419250077 - Fax 0419210586 mail@fmhconsulting.ch - www.fmhservices.ch 